\title{
Insulin-like growth factor 1 promotes neurological functional recovery after spinal cord injury through inhibition of autophagy via the PI3K/Akt/mTOR signaling pathway
}

\author{
DUO ZHANG $^{1 *}$, YUAN YUAN ${ }^{2 *}$, JICHAO ZHU $^{1}$, DI ZHU ${ }^{1}$, CHENXI LI $^{1}$,

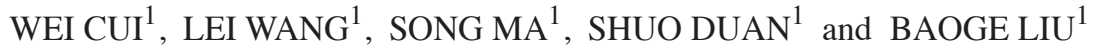 \\ ${ }^{1}$ Department of Orthopedics, Beijing Tiantan Hospital, Capital Medical University, Beijing 100070; \\ ${ }^{2}$ Department of Spinal Cord Injury Rehabilitation, China Rehabilitation Research Center, Beijing 100068, P.R. China
}

Received December 27, 2020; Accepted July 8, 2021

DOI: 10.3892/etm.2021.10700

\begin{abstract}
Spinal cord injury (SCI) is a serious trauma; however, the mechanisms underlying the role of insulin-like growth factor 1 (IGF-1) in autophagy following SCI remain to be elucidated. The present study aimed to investigate the therapeutic effect of IGF-1 on SCI and to determine whether IGF-1 regulates autophagy via the PI3K/Akt/mTOR signaling pathway. SH-SY5Y neuroblastoma cells were assigned to the $\mathrm{H}_{2} \mathrm{O}_{2}$, IGF-1 and control groups to investigate subsequent neuron injury in vitro. An MTT assay was performed to evaluate cell survival. In addition, Sprague-Dawley rats were randomly assigned to SCI, SCI + IGF-1 and sham groups, and Basso-Beatlie-Bresnahan scores were assessed to determine rat neurological function. Western blotting was used to analyze the autophagy level and the activation of the PI3K/Akt/mTOR signaling pathway. Cell survival was increased significantly in the IGF-1 group compared with the control group in vitro $(\mathrm{P}<0.05)$. Furthermore, neurological function was improved in the SCI + IGF-1 group compared with the control group in vivo $(\mathrm{P}<0.05)$. The western blotting results further demonstrated that LC3II/LC3I expression was increased in the IGF-1 group compared with the sham group in vivo and compared with the control group in vitro (both $\mathrm{P}<0.05$ ). In the $\mathrm{SCI}+\mathrm{IGF}-1$ group, the expression levels of PI3K, phosphorylated (p)-Akt and p-mTOR were higher compared with those in the sham and SCI groups in vivo $(\mathrm{P}<0.05)$. Moreover, in the IGF-1 group, the expression levels of p-Akt and p-mTOR were higher compared with the control and the $\mathrm{H}_{2} \mathrm{O}_{2}$ groups in vitro $(\mathrm{P}<0.05)$. Collectively, the
\end{abstract}

Correspondence to: Dr Baoge Liu, Department of Orthopedics, Beijing Tiantan Hospital, Capital Medical University, 119 South Fourth Ring West Road, Fengtai, Beijing 100070, P.R. China E-mail: baogeliu@hotmail.com

${ }^{*}$ Contributed equally

Key words: spinal cord injury, insulin-like growth factor 1 , autophagy, PI3K/Akt/mTOR signaling pathway, functional recovery results of the present study suggested that IGF-1 promoted functional recovery in rats following SCI through neuroprotective effects. Furthermore, the underlying mechanism may involve activation of the PI3K/Akt/mTOR signaling pathway, followed by inhibition of autophagy. However, further investigation into the association between IGF-1-regulated autophagy and the activation of different subtypes of PI3K is required.

\section{Introduction}

Spinal cord injury (SCI) has been considered one of the most severe types of central nervous system (CNS) injury that directly or indirectly results in impairment of motor, sensory and other functions (1). However, there is currently a lack of effective therapeutic methods for the treatment of SCI, including medicine or surgery $(2,3)$. SCI is characterized by a disruption in the arrangement, type and number of cells at the injury sites (4). Thus, therapeutic targets should focus on the retention of neural cells at the injury site (5). Although it has been reported previously that scaffolds with neural stem cells improved rat locomotor function, the first choice of therapeutics in a clinical setting is to promote cell survival or generate additional neural cells (6).

Insulin-like growth factors (IGFs) serve a crucial role in the survival and integrity of neurons that promote recovery in several disease models, such as hypoxia/ischemia brain injury, multiple sclerosis and Alzheimer's disease (7,8). IGF-1 regulates a number of important neurophysiological activities, including neurogenesis, cytoplasmic synthesis and complex cognitive function $(9,10)$. Moreover, IGF-1 is a major growth factor for primary neural cells in the CNS (11). The results of a previous study demonstrated that, together, IGF-1 and matrix molecule osteopontin facilitate robust axon regeneration via the PI3K pathway following optic nerve crush (12).

It has previously been reported that IGF-1 expression is decreased in patients with SCI (13), and that high IGF-1 expression levels in patients with SCI may contribute to improved functional recovery (14). Additionally, IGF-1 with osteopontin promoted mouse hind limb function following SCI with T10 lateral hemisection (15). Furthermore, IGF promoted the survival of oligodendrocytes in the spinal cord, and rats with SCI exhibited a quicker neurological recovery (16). 
The results of previous studies have demonstrated that autophagy is one of the key processes involved in cell survival, differentiation and homeostasis $(17,18)$. Autophagy serves an important role in the intracellular catabolic mechanism underlying the recycling of damaged organelles and senescent proteins following SCI $(19,20)$. Previous studies have further confirmed that dysfunction of autophagy increased neuronal apoptosis following SCI, indicating that autophagy may be involved in SCI (21,22). A number of signaling pathways are involved in autophagy, including the key PI3K/Akt/mTOR signaling pathway (23). Moreover, IGF-1 exerts its function via the PI3K/Akt/mTOR signaling pathway (24). Although it has previously been reported that IGF-1 exhibited therapeutic effects on neurological trauma, few studies have investigated the role and mechanism underlying IGF-1 in the treatment of SCI (25).

The present study aimed to investigate the neuroprotective and autophagic effects of IGF-1 on SCI, and to determine the role of the PI3K/Akt/mTOR signaling pathway in this process. Investigation into the role of IGF-1 in SCI may lead to the discovery of novel treatment options for SCI and further clinical applications of IGF-1.

\section{Materials and methods}

SH-SY5Y cell cultures. SH-SY5Y is a human derived neuroblastoma cell line that is often used to establish neuronal function and differentiation models in vitro (26). SH-SY5Y cells (cat. no. CL0278) were obtained from Hunan Fenghui Biotechnology Co., Ltd., and were evaluated by the short tandem repeat method. Cells were cultured in DMEM/F12 (Cytiva) supplemented with 10\% FBS (Zhejiang Tianhang Biotechnology, Co., Ltd.), 1\% penicillin-streptomycin (Cytiva) and $2 \mathrm{mM}$ L-Glutamine (Beyotime Institute of Biotechnology) at $37^{\circ} \mathrm{C}$ and $5 \% \mathrm{CO}_{2}(27,28)$. Trypsin (Thermo Fisher Scientific, Inc.) was prepared for cell separation.

SH-SY5Y cell injury model and IGF-1 interference. Oxidative stress is one of the most important mechanisms underlying SCI, and $\mathrm{H}_{2} \mathrm{O}_{2}$ is used for simulating oxidative stress in cells in vitro (29). There were three groups, $\mathrm{H}_{2} \mathrm{O}_{2}$ group, IGF-1 group and control group. Following culture of the three groups of SH-SY5Y cells $\left(5 \times 10^{4} / \mathrm{ml}\right)$ in 96 -well plates for $12 \mathrm{~h}$, supernatants were removed. In the control group, SH-SY5Y cells were incubated in the aforementioned neural media (DMEM/F12 with FBS, penicillin-streptomycin and L-Glutamine) for 6,12 and $24 \mathrm{~h}$ at $37^{\circ} \mathrm{C}$ and $5 \% \mathrm{CO}_{2}$. In the $\mathrm{H}_{2} \mathrm{O}_{2}$ group, cells were incubated in neuronal media supplemented with $200 \mu \mathrm{mol} / 1 \mathrm{H}_{2} \mathrm{O}_{2}$ for 6,12 and $24 \mathrm{~h}$ at $37^{\circ} \mathrm{C}$ and $5 \% \mathrm{CO}_{2}$ (28). In the IGF-1 group, cells were incubated in neuronal media supplemented with $200 \mu \mathrm{mol} / 1 \mathrm{H}_{2} \mathrm{O}_{2}$ and $100 \mathrm{ng} / \mathrm{ml} \mathrm{IGF-1} \mathrm{(Sigma-Aldrich;} \mathrm{Merck} \mathrm{KGaA)} \mathrm{for} \mathrm{6,} 12$ and $24 \mathrm{~h}$ at $37^{\circ} \mathrm{C}$ and $5 \% \mathrm{CO}_{2}(30,31)$. This concentration of IGF-1 was selected using preliminary tests (data not shown). At $6 \mathrm{~h}$ following cell injury, cells were washed with PBS twice and collected for western blot analysis, and at 6,12 and 24 h, cell samples were used for the MTT assays.

MTT assay. An MTT assay was performed to examine cell survival following injury and IGF-1 interference. Cell culture medium was removed from each well of the 96-well-plate as aforementioned, and cells were incubated for $4 \mathrm{~h}$ at $37^{\circ} \mathrm{C}$ in the $\mathrm{CO}_{2}(5 \%)$ incubator, followed by the addition of $20 \mu \mathrm{l} \mathrm{MTT}$ reagent $(5 \mathrm{mg} / \mathrm{ml})$ for a further incubation at $37^{\circ} \mathrm{C}$ for $4 \mathrm{~h}$. Following the MTT incubation, $150 \mu 120 \%$ DMSO was added to each well to remove the purple formazan crystals. The plate was subsequently shaken for $10 \mathrm{~min}$ for solubilization. The absorbance was measured using a microplate spectrophotometer at a wavelength of $490 \mathrm{~nm}$. The final optical density was calculated using the average of six wells.

Animal care and groups. In total, 24 healthy adult male Sprague-Dawley rats (age, 8-12 weeks; weight, 240-280 g) were purchased from Shanghai Jieyi Biotechnology, Co., Ltd., and used for the SCI model generation. All rats were housed in a specific-pathogen-free laboratory under a 12-h light/dark cycle and a stable temperature of $23-25^{\circ} \mathrm{C}$. All animals were housed individually and had free access to standard food and water. All experimental procedures were performed in accordance with the Guiding Opinions on the Ethical Treatments of Laboratory Animals published by the Ministry of Science and Technology of the People's Republic of China in 2006 (32). All animal protocols were approved by the Animal Ethics Committee of Capital Medical University of China (approval no. PYZ2017082).

The rats were assigned into sham $(n=8)$, SCI $(n=8)$ and $\mathrm{SCI}+\mathrm{IGF}-1(\mathrm{n}=8)$ groups using a random numbers table. In total, five rats were randomly selected from each group for Basso-Beatlie-Bresnahan (BBB) score evaluation, and the remaining three rats in each group were sacrificed for western blot analysis at 1 day after SCI modeling.

SCImodel and IGF-1 treatment. Rats in the SCI and SCI+ IGF-1 groups received an SCI operation, which was conducted as previously described $(33,34)$. Briefly, after anesthetization with $4 \%$ sodium pentobarbital [ $50 \mathrm{mg} / \mathrm{kg}$; intraperitoneal (i.p.) injection], rats were placed on a heating pad to maintain body temperature. The spine at T9-11 was exposed from the dorsal side and a laminectomy was performed. A 10-g rod was freely dropped from a height of $25 \mathrm{~mm}$, which was controlled by an NYU Impactor II (New York University Medical Center, New York, NY, USA), to impact the T10 segment of the spinal cord; wagging tail reflex and lower limb spasms were observed. Laminectomy was performed on the rats in the sham group without SCI (35). The wound was sutured layer by layer. Manual bladder emptying was performed and an i.p. injection of $20 \mathrm{U} / \mathrm{kg}$ penicillin was administered once daily until bladder function was re-established.

Rats were administered an i.p. injection of $1 \mathrm{ml} \mathrm{IGF-1}$ ( $50 \mathrm{~g} / \mathrm{kg}$; dissolved in 0.9\% NaCl; Sigma-Aldrich; Merck KGaA) $<5$ min after SCI operation (36,37). This concentration was selected in preliminary tests (data not shown). This was repeated once daily in the SCI + IGF-1 group until animals were sacrificed (36). At the same time, an i.p. injection of $1 \mathrm{ml} 0.9 \% \mathrm{NaCl}$ was administered to rats in the sham and SCI groups. All the procedures were performed by the same unblinded investigator.

Neurological function assessment. The neurological function of the rats was assessed using the BBB rating scale, which was described in our previous studies $(33,34)$. The BBB score ranged from 0 (complete paralysis) to 21 (healthy) (38). In total, two blinded, independent examiners evaluated the BBB score 
before the operation and again at 1 day, and 1,2,3 and 4 weeks following SCI. The average score was used for subsequent analysis. After 4 weeks, an i.p. injection of $300 \mathrm{mg} / \mathrm{kg}$ sodium pentobarbital was used to sacrifice the rats.

Collection of the specimens. Based on the results of previous studies and our previous research, autophagy is altered and increases quickly following SCI, reaching a peak on day $1(20,34)$. On day 1 after the initial treatment of IGF-1, rats were anesthetized with $4 \%$ sodium pentobarbital (50 mg/kg; i.p. injection) followed by an intracardiac perfusion with normal saline $(0.9 \% \mathrm{NaCl})$. After $\mathrm{SCI}$, the injury area expanded and the injury margin was more difficult to clearly distinguish (39). Thus, a 10-mm segment of spinal cord tissue centered at the injury site was removed. An i.p. injection of $300 \mathrm{mg} / \mathrm{kg}$ sodium pentobarbital was subsequently used to sacrifice the rats. The spinal cord tissue was immediately frozen in liquid nitrogen and stored at $-80^{\circ} \mathrm{C}$.

Western blot analysis. Protein determination was performed by western blot analysis. Each specimen was handled individually for the following procedures. RIPA lysis buffer was used for purification of total proteins from the spinal cord specimens. The 10-mm spinal cord tissue and each group of the SH-SY5Y cell samples were dissolved in ice-cold RIPA lysis buffer containing PMSF(Beyotime Institute of Biotechnology). Protein concentration was determined by BCA kit (Beyotime Institute of Biotechnology). Homogenates of spinal cord specimens and cell samples were centrifuged at $13,500 \mathrm{x}$ g for $30 \mathrm{~min}$ at $4^{\circ} \mathrm{C}$ to collect the supernatant. A total of $50 \mu \mathrm{g}$ protein per lane was separated by SDS-PAGE on $15 \%$ gel $(80 \mathrm{~V}$ for $30 \mathrm{~min}$; followed by $120 \mathrm{~V}$ for $90 \mathrm{~min}$ ) and transferred onto a PVDF membrane (Beyotime Institute of Biotechnology). The membranes were blocked with $5 \%$ non-fat milk in TBS with $0.1 \%$ Tween-20 for $2 \mathrm{~h}$ at $25^{\circ} \mathrm{C}$. Subsequently, the membranes were incubated with the following antibodies: GAPDH (1:5,000; cat. no. ab8245; Abcam), anti-LC3I/II (1:1,500; cat. no. ab52768; Abcam), anti-PI3K (1:1,000; cat. no. ab191606; Abcam), anti-Akt (1:1,000; cat. no. ab8805; Abcam), anti-phosphorylated (p)-Akt (1:1,000; cat. no. ab81283; Abcam), anti-mTOR (1:1,000; cat. no. ab134903; Abcam) and anti-p-mTOR (1:1,000; cat. no. ab137133; Abcam) at $4^{\circ} \mathrm{C}$ overnight. Subsequently, the membranes were washed three times with TBST (0.2\% Tween-20) and incubated with HRP-conjugated IgG secondary antibody (1:5,000; cat. no. ab97051; Abcam) at $25^{\circ} \mathrm{C}$ for $1 \mathrm{~h}$. Following secondary incubation, the membranes were washed again, and proteins were visualized using ECL solution (Beyotime Institute of Biotechnology). Images were captured using a ChemiDoc-It ${ }^{\mathrm{TM}}$ TS2 Imager (Analytik Jena $\mathrm{GmbH}$ ). ImageJ software version 2 (National Institutes of Health) was used to measure the density of the scanned protein bands, with GAPDH used for normalization. All the procedures were performed by the same blinded investigator.

Statistical analysis. Experimental data are presented as the mean \pm SD, and all data were analyzed using SPSS software version 23.0 (IBM Corp.). Comparison of BBB score among three groups was performed using a non-parametric Kruskal-Wallis test followed by Dunn's post hoc test. Additional comparisons among three groups were performed

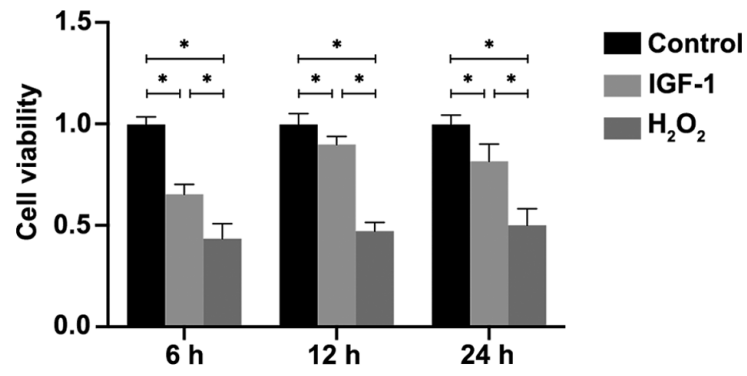

Figure 1. Assessment of cell viability using an MTT assay in vitro. Cell viability of the IGF-1 group is significantly increased compared with the $\mathrm{H}_{2} \mathrm{O}_{2}$ group at 6,12 and $24 \mathrm{~h}$. ${ }^{*} \mathrm{P}<0.05$. IGF-1, insulin-like growth factor 1 .

A

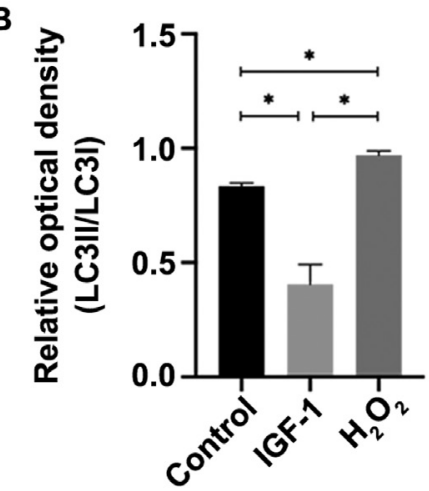

Figure 2. Western blot analysis of autophagy-related proteins in vitro. $\mathrm{H}_{2} \mathrm{O}_{2}$-induced $(6 \mathrm{~h})$ SH-SY5Y cell SCI models were treated with or without IGF-1. (A) Representative western blotting results of LC3I and LC3II expression and (B) semi-quantification of the LC3II/LC3I ratio in each group. Data are expressed as the mean $\pm \mathrm{SD}$. Experiments were performed in triplicate. $\mathrm{n}=3$ per group. ${ }^{*} \mathrm{P}<0.05$. IGF-1, insulin-like growth factor 1 .

using a one-way ANOVA followed by a least significant difference post hoc test. $\mathrm{P}<0.05$ was considered to indicate a statistically significant difference.

\section{Results}

IGF-1 promotes cell survival in vitro. To simulate the microcirculation in SCI, SH-SY5Y cells were exposed to $200 \mu \mathrm{mol} / 1$ $\mathrm{H}_{2} \mathrm{O}_{2}$ for 6,12 and $24 \mathrm{~h}$ to establish a neural cell injury model in vitro. The MTT assay results indicated that the cell viability was significantly decreased in the $\mathrm{H}_{2} \mathrm{O}_{2}$ and IGF-1 groups compared with the control group at 6, 12 and $24 \mathrm{~h}$ (all $\mathrm{P}<0.05$; Fig. 1). Furthermore, viability was significantly higher in the IGF-1 group compared with the $\mathrm{H}_{2} \mathrm{O}_{2}$ group $(\mathrm{P}<0.05$; Fig. 1).

IGF-1 activates the PI3K/Akt/mTOR signaling pathway to reduce autophagy in vitro. The expression levels of autophagy-associated proteins were measured to evaluate the effect of IGF-1 on autophagy and to identify the mechanisms underlying SH-SY5Y cells following exposure to $\mathrm{H}_{2} \mathrm{O}_{2}$ and co-treatment of IGF-1 for $6 \mathrm{~h}$. The results demonstrated that LC3II/LC3I expression was significantly increased in the $\mathrm{H}_{2} \mathrm{O}_{2}$ group compared with the control $(\mathrm{P}<0.05)$, whereas it was significantly decreased in the IGF-1 group compared with the $\mathrm{H}_{2} \mathrm{O}_{2}$ and control groups (both $\mathrm{P}<0.05$; Fig. $2 \mathrm{~A}$ and $\mathrm{B}$ ) at $6 \mathrm{~h}$ after cells injury. 
A

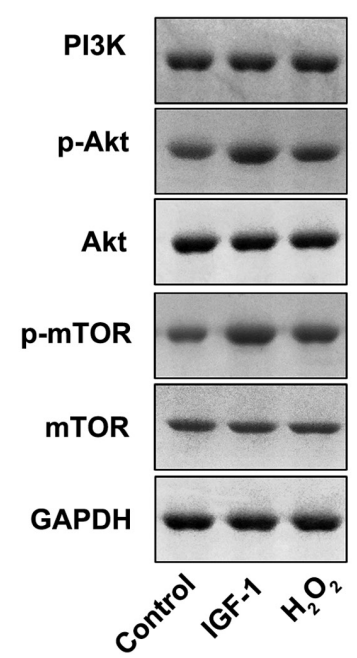

B

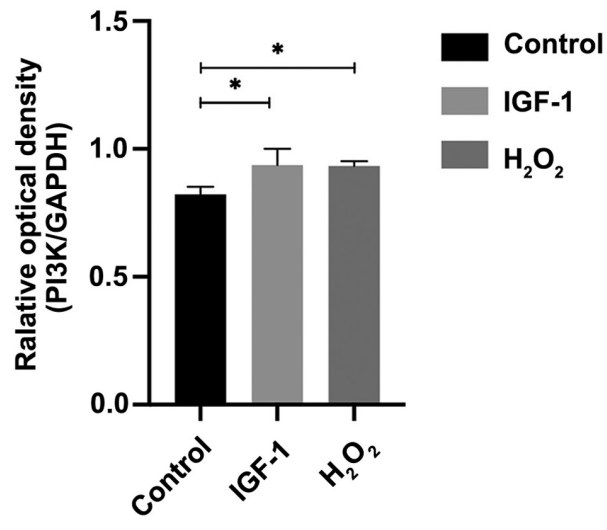

C

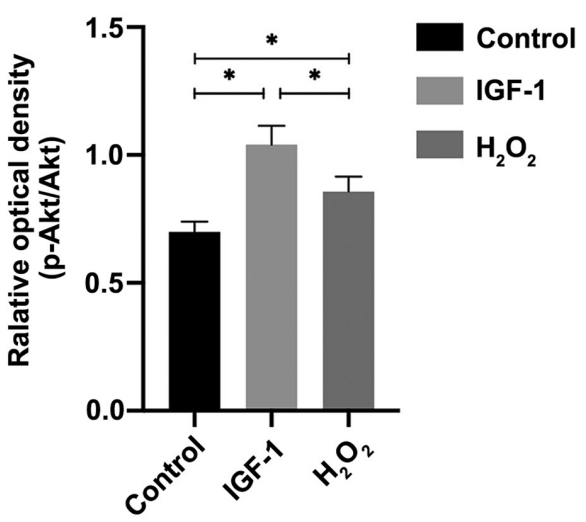

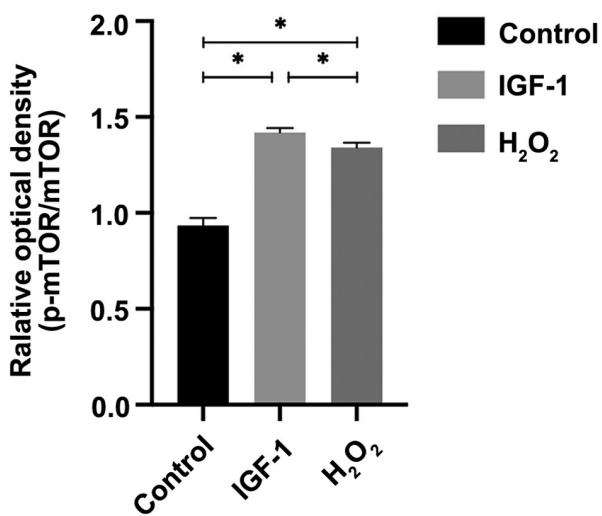

Figure 3. Western blot analysis of the effects of IGF-1 on the PI3K/Akt/mTOR signaling pathway in vitro $\mathrm{H}_{2} \mathrm{O}_{2}$-induced (6 h) SH-SY5Y cell SCI models were treated with or without IGF-1. (A) Representative western blotting images and semi-quantification of (B) PI3K, (C) p-Akt/Akt and (D) p-mTOR/mTOR expression in each group. Data are expressed as the mean \pm SD. Experiments were performed in triplicate. ${ }^{*} \mathrm{P}<0.05$. IGF-1, insulin-like growth factor 1; p-, phosphorylated.

To study the role of the PI3K/Akt/mTOR signaling pathway in IGF-1-induced inhibition of autophagy, activation of the pathway was determined using western blotting. As presented in Fig. 3, PI3K expression was increased significantly in the IGF-1 group compared with the control $(\mathrm{P}<0.05)$. In the same trend as PI3K expression, p-Akt/Akt and p-mTOR/mTOR expression was increased in the IGF-1 group compared with both the $\mathrm{H}_{2} \mathrm{O}_{2}$ and control groups $(\mathrm{P}<0.05)$.

Overall, these data suggested that IGF-1 may activate the $\mathrm{PI} 3 \mathrm{~K} / \mathrm{Akt} / \mathrm{mTOR}$ signaling pathway, which resulted in downregulation of autophagy.

Neurological functional recovery. In the SCI model rats, lower hindlimb function was evaluated using the BBB scale 1 day before SCI, and at 1 day and 1,2,3 and 4 weeks after SCI. Following SCI, the locomotor function score of rats was zero in the SCI + IGF-1 and SCI groups at 1 day after SCI, which gradually improved over time in these groups (Fig. 4). Although there was no significant difference between the $\mathrm{SCI}+\mathrm{IGF}-1$ and SCI groups at 1 day and 1 week $(\mathrm{P}>0.05)$, rats in the SCI + IGF-1 group exhibited significantly improved neurological functional recovery compared with the SCI group at 2, 3 and 4 weeks $(\mathrm{P}<0.05$; Fig. 4).

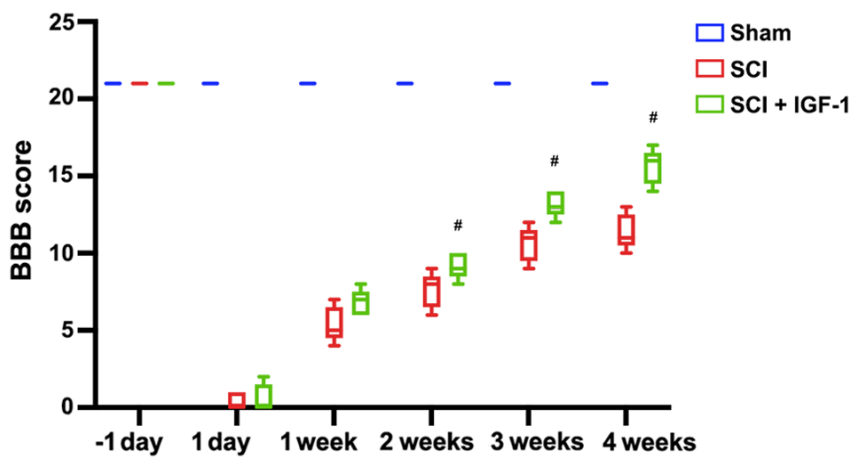

Figure 4. Effects of IGF-1 on locomotor functional recovery in rats after SCI. The IGF-1 group received IGF-1 treatment $(50 \mu \mathrm{g} / \mathrm{kg})$ daily following SCI, whereas an intraperitoneal injection of $0.9 \% \mathrm{NaCl}$ was administered to the SCI and sham groups. BBB scores are represented as the median and interquartile range; $\mathrm{n}=5$ rats/group. $\mathrm{BBB}$ scores were evaluated at -1 day before SCI and at 1 day and $1,2,3$ and 4 weeks after SCI. ${ }^{~} \mathrm{P}<0.05$ vs. SCI group. BBB, Basso-Beatlie-Bresnahan; IGF-1, insulin-like growth factor 1; SCI, spinal cord injury.

IGF-1 inhibits autophagy via the PI3K/Akt/mTOR signaling pathway following SCI in vivo. LC3II and LC3I expression levels were evaluated by western blot analysis on day 1 after 
A

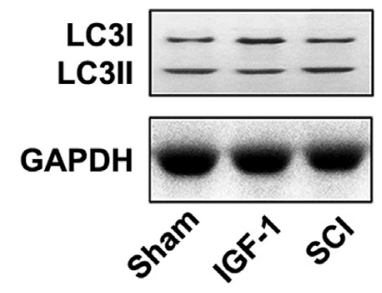

B

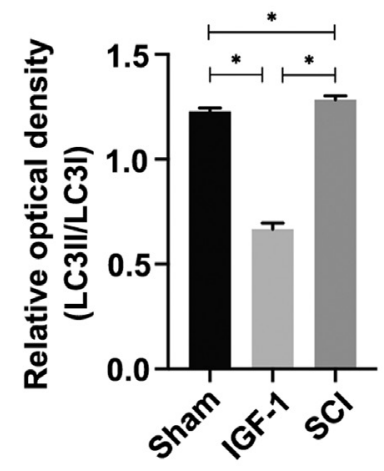

Figure 5. Western blot analysis of the expression levels of autophagy-related proteins in vivo. Protein expression was examined in injured spinal cords were at 1 day after SCI with or without IGF-1 treatment. (A) Protein expression levels of LC3I and LC3II and (B) semi-quantification of the LC3II/LC3I ratio in each group. Data are expressed as the mean $\pm S D ; n=3$ rats/group. ${ }^{*} \mathrm{P}<0.05$. IGF-1, insulin-like growth factor 1 ; SCI, spinal cord injury.

SCI. The expression level of LC3II/LC3I was significantly lower in the SCI + IGF-1 sham group compared with sham group, whereas it was significantly higher in the SCI group compared with the sham group $(\mathrm{P}<0.05$; Fig. 5).

To evaluate the activation of the PI3K/Akt/mTOR signaling pathway, the relative expression level of PI3K and the ratios of $\mathrm{p}-\mathrm{Akt} / \mathrm{Akt}$ and $\mathrm{p}-\mathrm{mTOR} / \mathrm{mTOR}$ expression were analyzed. Following SCI, the relative expression levels of PI3K, p-Akt and p-mTOR were higher compared with the expression levels in the sham group (all $\mathrm{P}<0.05$ ). However, the relative expression levels of $\mathrm{p}-\mathrm{Akt} / \mathrm{Akt}$ and $\mathrm{p}-\mathrm{mTOR} / \mathrm{mTOR}$ in the $\mathrm{SCI}+\mathrm{IGF}-1$ group were significantly higher compared with the expression levels in the untreated SCI group (all $\mathrm{P}<0.05$; Fig. 6).

\section{Discussion}

IGF-1 is an inherent molecule of the insulin family that has numerous physiological functions in the human body, such as regulating growth, insulin sensitivity and cardiovascular activity (40). Moreover, IGF-1 regulates various neurological activities, such as neuronal survival, energy metabolism and plasticity (41). In addition, IGF-1 is a potent growth factor for different types of nerve cells (42). A higher expression level of IGF-1 in patients with SCI may improve functional recovery (14).

A significant decrease in serum IGF-1 levels was observed in patients with SCI compared with physiological range $(13,43)$, and Ferbert et al (43) reported that patients with higher IGF-1 levels exhibited improved neurological recovery at 12 weeks following SCI. The results of another study indicated that the IGF-1 concentration in the plasma and injured spinal cord of SD rats was significantly decreased compared with the control group, and the administration of exogenous IGF-1 reduced cell damage after SCI (44). The results of the present study are consistent with these previous data; the neurological function of SCI rats receiving treatment with IGF-1 recovered to a greater extent compared with untreated SCI rats. However, the role of IGF-1 and the underlying mechanisms are yet to be fully elucidated.

It has been reported that autophagy serves an important role in the process of cell death $(45,46)$. The present study was conducted to examine the inhibitory effect of IGF-1 on autophagy as a therapy for SCI and aimed to elucidate the potential underlying mechanisms. The results of the present study demonstrated that IGF-1 promoted functional recovery in SCI rats and increased the number of surviving neural cells following injury in vitro. In vivo and in vitro results demonstrated that IGF-1 inhibited autophagy, with higher expression levels of p-Akt and p-mTOR. These findings indicated that IGF-1 may inhibit autophagy via the PI3K/Akt/mTOR signaling pathway.

However, the detailed mechanisms underlying autophagy in cell death and survival remain a matter of debate (47-50). Autophagy involves a series of complex processes, such as the delivery of cytoplasmic cargo sequestered inside double-membrane vesicles to the lysosome, which is a dynamic equilibrium and changes rapidly from one stage to the other. The process is hard to monitored in real-time accurately. The intensity, timing and regulating mechanisms underlying autophagy may have protective effects or may aggravate damage in cells $(20,51)$. At present, it is recognized that autophagy is increased following SCI $(52,53)$. However, it has been demonstrated by various studies that the same interference may lead to different outcomes (18). On the one hand, a number of studies reported that the therapeutic effects of various methods, like rapamycin, simvastatin, lithium, were based on increased autophagy, which protected a larger number of neural cells from death $(20,34,54,55)$. On the other hand, the results of previous studies have indicated that increased autophagy was the cause of neural cell death, as it has been observed that inhibition of autophagy promoted neurological functional recovery $(20,56,57)$.

The present study demonstrated that IGF-1 treatment improved neurological function following SCI. IGF-1 is involved in neural cell proliferation, clearance of abnormal cells, inflammation, myelination, neurogenesis and plasticity (24,58-61). Moreover, the results of the present study demonstrated that IGF-1 may improve neurological function via the $\mathrm{PI} 3 \mathrm{~K} / \mathrm{Akt} / \mathrm{mTOR}$ signaling pathway and inhibition of autophagy.

In addition to the aforementioned functions of IGF-1, it has been reported that antagonism of the IGF-1 receptor inhibits rather than induces autophagy (62). A potential factor that may affect the function of the IGF-1 signaling pathway in autophagy includes the existence of different types of PI3K proteins, which function in different manners (63). The PI3K family comprises kinases that are key to the regulation of autophagy, and they are divided into three classes. Class I PI3K proteins have been largely described and activate the Akt/mTOR signaling pathway that inhibits autophagy (64). Class II PI3K proteins are involved in a wide variety of biological activities. For example, PI3K-C2a participates in glucose transportation, secretion of insulin, release of neurosecretory granules, endocytosis and contraction of muscle cells; $\mathrm{PI} 3 \mathrm{~K}-\mathrm{C} 2 \mathrm{~b}$ is active in cell migration and potassium channel activation; and both PI3K-C2a and PI3K-C2b are involved in cell proliferation and survival (65). Moreover, PI3K-C2 is involved in autophagy (66). It has previously been reported that both the Class II and Class III PI3K proteins enhance 
A

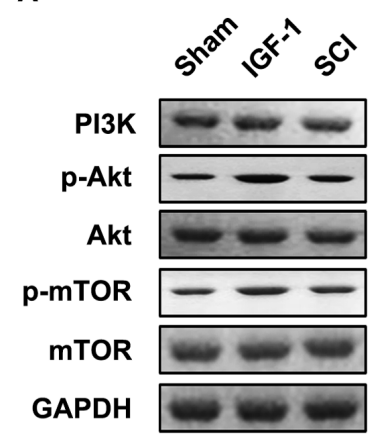

C

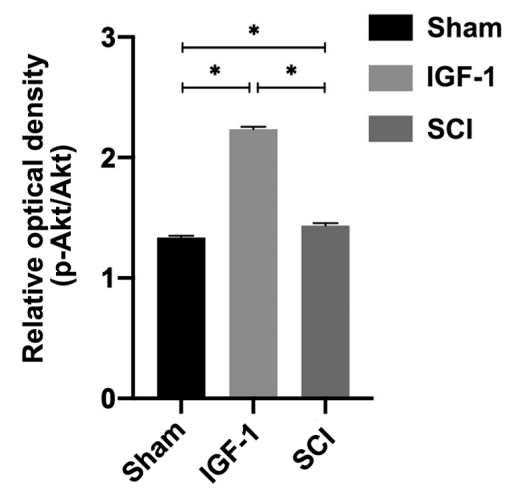

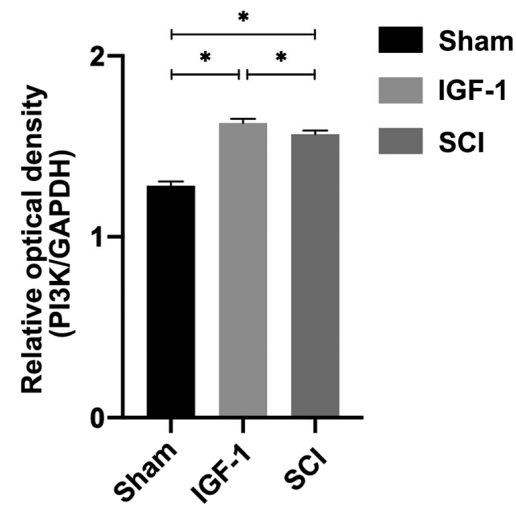

D

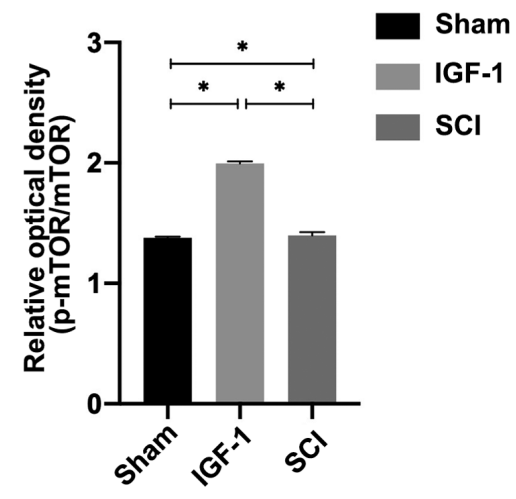

Figure 6. Western blot analysis of the effects of IGF-1 on the PI3K/Akt/mTOR signaling pathway in vivo. Protein expression was examined in injured spinal cords at 1 day after SCI with or without IGF-1 treatment. (A) Western blotting results of the PI3K, Akt, p-Akt, mTOR and p-mTOR protein expression levels. (B) Relative protein expression levels of PI3K. (C) Ratio of p-Akt and Akt protein expression levels. (D) Ratio of p-mTOR and mTOR protein expression levels. Data are expressed as the mean $\pm \mathrm{SD} ; \mathrm{n}=3$ rats/group. ${ }^{*} \mathrm{P}<0.05$. IGF-1, insulin-like growth factor 1; $\mathrm{p}-$, phosphorylated; SCI, spinal cord injury.

autophagy (67). In addition, Class I proteins contribute to the formation of phosphatidylinositol-3-phosphate (PI3P), which is the key secondary messenger in autophagy and is further affected and regulated by the Class II and Class III PI3Ks (68).

Different types of cells, such as neurons, astrocytes and oligodendrocytes in the spinal cord produce different responses to harmful stimuli and varying activation of the same signaling pathway, including autophagy. Neurons would suffer apoptosis after damage, while the astrocytes would proliferate and secrete neurotrophic factors (69). The results of a previous study demonstrated that the expression of p-Akt was increased at $6 \mathrm{~h}$ after contusion rat SCI in neurons, reaching a peak at 3 days, before returning to baseline. However, the increase in the expression of p-Akt was initiated at 3 days and continued until 7 days after SCI in astrocytes (70). The characteristics of autophagy vary amongst different neural cells involved in SCI. A higher level of autophagy was found in neurons at $3 \mathrm{~h}$ following SCI (26), whereas Hou et al (71) observed an increased level of autophagy in astrocytes at 3 days after SCI. Moreover, no increase of autophagy was observed in astrocytes at 4 days after SCI with enhanced autophagy, but the glial scar was reduced at 2 weeks after SCI $(72,73)$. The results of a previous study revealed that changes in neuronal autophagy are associated with the neuronal subtype, and neurons from the spinal cord may be affected more easily by the inhibition of autophagic flux compared with brain neurons (53). Previous studies have also demonstrated that the accumulation of autophagosomes in oligodendrocytes was observed at later timepoints compared with neurons, suggesting that the reaction to damage is not the same between these two cells $(21,74,75)$. Thus, it was suggested that autophagy is a dynamic process, which exerts positive or negative effects in early or late stages $(20,76)$. Fang et al (76) reported that neurological function was improved when autophagy was stimulated at an early stage after SCI, compared with poor neurological function when autophagy was inhibited at the early stage. However, neurological function was not improved when autophagy was stimulated at a late stage compared with improved neurological function when autophagy was inhibited at the same stage following SCI.

IGF-1 has been applied in the clinical setting for the treatment of growth failure in pediatric patients with severe primary IGF-1 deficiency and in patients with growth hormone (GH) gene deletion who have developed neutralizing antibodies to GH (77,78). IGF-1 is safe and positively effects body composition, and IGF-1 treatment for SCI in the clinical setting is easily accessible, which has been approved by The Food and Drug Administration (FDA) (34). Based on previous studies and the results of the present study, IGF-1 has potential as a clinical treatment of SCI. However, determining the optimal timing for IGF-1 treatment requires further investigation.

The present study is the first to report the effect of IGF-1 on autophagy in treating SCI involving the PI3K/Akt/mTOR signaling pathway. However, the current study presents preliminary evidence lacking deep exploration, thus, further investigation is required. In future studies, the duration of 
the BBB scoring experiment will be extended to 2 months. Additionally, inhibitors of PI3K, Akt, mTOR and the IGF-1 receptor will be used to confirm the impact of IGF-1 and mechanisms underlying this protein in the PI3K/Akt/mTOR signaling pathway. Although the BBB scale is widely used to evaluate neurological function, it is a subjective tool. More objective techniques involve measurement of the neurological regeneration, including immunofluorescence staining of regenerated nerve fibers, examination of the myelinated axon density, electrophysiological tests and diffusion tensor imaging $(33,79)$.

In conclusion, the present study demonstrated that IGF-1 promoted functional recovery in rats after SCI and exerted neuroprotective effects. Furthermore, the IGF-1-induced inhibition of autophagy may be associated with activation of the PI3K/Akt/mTOR signaling pathway. However, whether the regulation of autophagy by IGF-1 is associated with the activation of different PI3K signaling pathways in different neural cells at varying injury stages remains to be elucidated and requires further investigation.

\section{Acknowledgements}

The authors would like to thank Dr Fang Wang from Xi'an Jiaotong University of China (Xi'an China) for technical support.

\section{Funding}

This work was supported by The Beijing Excellent Talent Training Funding (grant no. 2017000021469G215), The Natural Science Foundation of Capital Medical University of China (grant nos. PYZ2017082; PYZ2018081) and China Rehabilitation Research Center Foundation (grant no. 2018zx-Q3).

\section{Availability of data and materials}

The datasets used and/or analyzed during the current study are available from the corresponding author on reasonable request.

\section{Authors' contributions}

DZha and YY conceived the project. DZha, DZhu, CL and SD performed the animal and cell experiments. DZha, YY and JZ integrated and analyzed the experimental data. DZha, YY and BL conceived and designed the study. DZha drafted the manuscript. JZ, LW, SM and WC performed the statistical analysis. BL and DZha confirm the authenticity of all the raw data. All authors have read and approved the final manuscript.

\section{Ethics approval and consent to participate}

All experimental procedures were performed in accordance with the Guidelines for the Care and Use of Laboratory Animals (Institute for Laboratory Animal Research, National Academy of Science). The protocols were approved by the Animal Ethics Committee of Capital Medical University of China (Beijing, China; approval no. PYZ2017082).

\section{Patient consent for publication}

Not applicable.

\section{Competing interests}

The authors declare that they have no competing interests.

\section{References}

1. Casili G, Campolo M,Lanza M, Filippone A, Scuderi S, Messina S Ardizzone A, Esposito E and Paterniti I: Role of ABT888, a Novel Poly(ADP-Ribose) Polymerase (PARP) Inhibitor in Countering Autophagy and Apoptotic Processes Associated to Spinal Cord Injury. Mol Neurobiol 57: 4394-4407, 2020.

2. Duncan GJ, Manesh SB, Hilton BJ, Assinck P, Plemel JR and Tetzlaff $\mathrm{W}$ : The fate and function of oligodendrocyte progenitor cells after traumatic spinal cord injury. Glia 68: 227-245, 2020.

3. Imai T, Katoh H, Suyama K, Kuroiwa M, Yanagisawa S and Watanabe M: Amiloride promotes oligodendrocyte survival and remyelination after spinal cord injury in rats. J Clin Med 7: 7, 2018.

4. Zhou K, Sansur CA, Xu H and Jia X: The Temporal Pattern, Flux, and Function of Autophagy in Spinal Cord Injury. Int J Mol Sci 18: 466, 2017.

5. Silva NA, Sousa N, Reis RL and Salgado AJ: From basics to clinical: A comprehensive review on spinal cord injury. Prog Neurobiol 114: 25-57, 2014.

6. Ham TR, Pukale DD, Hamrangsekachaee M and Leipzig ND: Subcutaneous priming of protein-functionalized chitosan scaffolds improves function following spinal cord injury. Mater Sci Eng C Mater Biol Appl 110: 10.1016/j.msec.2020.110656, 2020.

7. Aleman A and Torres-Alemán I: Circulating insulin-like growth factor I and cognitive function: Neuromodulation throughout the lifespan. Prog Neurobiol 89: 256-265, 2009.

8. Russo VC, Gluckman PD, Feldman EL and Werther GA: The insulin-like growth factor system and its pleiotropic functions in brain. Endocr Rev 26: 916-943, 2005.

9. Liu W, D'Ercole JA and Ye P: Blunting type 1 insulin-like growth factor receptor expression exacerbates neuronal apoptosis following hypoxic/ischemic injury. BMC Neurosci 12: 64, 2011.

10. O'Donnell SL, Frederick TJ, Krady JK, Vannucci SJ and Wood TL: IGF-I and microglia/macrophage proliferation in the ischemic mouse brain. Glia 39: 85-97, 2002.

11. Huang TS, Wang YH and Lien IN: Suppression of the hypothalamus-pituitary somatotrope axis in men with spinal cord injuries. Metabolism 44: 1116-1120, 1995.

12. Petrova V and Eva R: The virtuous cycle of axon growth: Axonal transport of growth-promoting machinery as an intrinsic determinant of axon regeneration. Dev Neurobiol 78: 898-925, 2018.

13. Bauman WA, Kirshblum SC, Morrison NG, Cirnigliaro CM, Zhang RL and Spungen AM: Effect of low-dose baclofen administration on plasma insulin-like growth factor-I in persons with spinal cord injury. J Clin Pharmacol 46: 476-482, 2006.

14. Moghaddam A, Sperl A, Heller R, Kunzmann K, Graeser V, Akbar M, Gerner HJ and Biglari B: Elevated serum insulin-like growth factor 1 levels in patients with neurological remission after traumatic spinal cord injury. PLoS One 11: e0159764, 2016.

15. Liu Y, Wang X, Li W, Zhang Q, Li Y, Zhang Z, Zhu J, Chen B, Williams PR, Zhang Y, et al: A sensitized IGF1 treatment restores corticospinal axon-dependent functions. Neuron 95: 817-833.e4, 2017.

16. Fu C-F, Liu Y, Li X, Shen B, Zhang S-K, Song Z-M and Zhang X: Inhibitory effect of IGF-1 gene on motoneurons apoptosis in anterior horn after acute spinal cord injury in adult rats. 32nd edition. J Jilin Univeristy (Medicine) 4: 568-570, 2006 (In Chinese).

17. Mizushima N: Autophagy: Process and function. Genes Dev 21: 2861-2873, 2007.

18. Mizushima N and Komatsu M: Autophagy: Renovation of cells and tissues. Cell 147: 728-741, 2011.

19. Rao S, Tortola L, Perlot T, Wirnsberger G, Novatchkova M, Nitsch R, Sykacek P, Frank L, Schramek D, Komnenovic V, et al: A dual role for autophagy in a murine model of lung cancer. Nat Commun 5: 3056, 2014. 
20. Zhang D, Zhu D, Wang F, Zhu JC, Zhai X, Yuan Y and Li CX: Therapeutic effect of regulating autophagy in spinal cord injury: A network meta-analysis of direct and indirect comparisons. Neural Regen Res 15: 1120-1132, 2020.

21. Liu S, Sarkar C, Dinizo M, Faden AI, Koh EY, Lipinski MM and Wu J: Disrupted autophagy after spinal cord injury is associated with ER stress and neuronal cell death. Cell Death Dis 6: e1582, 2015.

22. Silva R, Mesquita AR, Bessa J, Sousa JC, Sotiropoulos I, Leão P, Almeida OF and Sousa N: Lithium blocks stress-induced changes in depressive-like behavior and hippocampal cell fate: The role of glycogen-synthase-kinase-3beta. Neuroscience 152: 656-669, 2008

23. Periyasamy-Thandavan S, Jiang M, Schoenlein P and Dong Z: Autophagy: Molecular machinery, regulation, and implications for renal pathophysiology. Am J Physiol Renal Physiol 297: F244-F256, 2009.

24. Zhang W, Liu Y, Wu M, Zhu X, Wang T, He K, Li P and Wu X: PI3K inhibition protects mice from NAFLD by down-regulating CMKLR1 and NLRP3 in Kupffer cells. J Physiol Biochem 73: 583-594, 2017

25. Kazanis I,Giannakopoulou M,Philippidis Hand Stylianopoulou F: Alterations in IGF-I, BDNF and NT-3 levels following experimental brain trauma and the effect of IGF-I administration. Exp Neurol 186: 221-234, 2004

26. Zhu M, Li B, Ma X, Huang C, Wu R, Zhu W, Li X, Liang Z, Deng F, Zhu J, et al: Folic acid protected neural cells against aluminum-maltolate-induced apoptosis by preventing miR-19 downregulation. Neurochem Res 41: 2110-2118, 2016.

27. Park KW, Lin C-Y, Benveniste EN and Lee Y-S: Mitochondrial STAT3 is negatively regulated by SOCS3 and upregulated after spinal cord injury. Exp Neurol 284 (Pt A): 98-105, 2016.

28. Zhang D, Zhai X, Wang F, Li XH and He XJ: Study of the neural protective effect of lithium on enhancement of autophagy in vitro. Zhongguo Gu Shang 32: 952-956, 2019 (In Chinese).

29. Zhaohui $C$ and Shuihua W: Protective effects of SIRT6 against inflammation, oxidative stress, and cell apoptosis in spinal cord injury. Inflammation 43: 1751-1758, 2020.

30. Wang Y, Wang W, Li D, Li M, Wang P, Wen J, Liang M, Su B and Yin Y: IGF-1 alleviates NMDA-induced excitotoxicity in cultured hippocampal neurons against autophagy via the NR2B/PI3K-AKT-mTOR pathway. J Cell Physiol 229: 1618-1629, 2014.

31. Huang D, Shen S, Cai M, Jin L, Lu J, Xu K, Zhang J, Feng G, $\mathrm{Hu}$ Y, Zheng K, et al: Role of mTOR complex in IGF-1 induced neural differentiation of DPSCs. J Mol Histol 50: 273-283, 2019.

32. Ministry of Science and Technology of the People's Republic of China:Guidance to Ethical Treatment of Animals for Experiments http://www.most.gov.cn/xxgk/xinxifenlei/fdzdgknr/fgzc/gfxwj/ gfxwj2010before/201712/t20171222_137025.html. Accessed August 19,2021 (In Chinese).

33. Zhang D, Li XH, Zhai X and He XJ: Feasibility of $3.0 \mathrm{~T}$ diffusion-weighted nuclear magnetic resonance imaging in the evaluation of functional recovery of rats with complete spinal cord injury. Neural Regen Res 10: 412-418, 2015.

34. Zhang D, Wang F, Zhai X, Li XH and He XJ: Lithium promotes recovery of neurological function after spinal cord injury by inducing autophagy. Neural Regen Res 13: 2191-2199, 2018.

35. Barros AGC, Cristante AF, Santos GBD, Natalino RJM, Ferreira RJR and Barros-Filho TEP: Evaluation of the effects of erythropoietin and interleukin-6 in rats submitted to acute spinal cord injury. Clinics (São Paulo) 74: e674, 2019.

36. Zhou L, Fan MD, Jiang J and Xue W: Effect of IGF-1 on cognitive function and apoptosis of hippocampal tissue neurons in rats with delayed neuropsychologic sequelae after carbon monoxide poisoning. J Brain Nerv Dis 27: 661-666, 2019.

37. Wang $\mathrm{S}$ and $\mathrm{Gu} \mathrm{K}$ : Insulin-like growth factor 1 inhibits autophagy of human colorectal carcinoma drug-resistant cells via the protein kinase $\mathrm{B} / \mathrm{mammalian}$ target of rapamycin signaling pathway. Mol Med Rep 17: 2952-2956, 2018.

38. Basso DM, Beattie MS and Bresnahan JC: A sensitive and reliable locomotor rating scale for open field testing in rats. J Neurotrauma 12: 1-21, 1995.

39. Turtle JD, Henwood MK, Strain MM, Huang YJ, Miranda RC and Grau JW: Engaging pain fibers after a spinal cord injury fosters hemorrhage and expands the area of secondary injury. Exp Neurol 311: 115-124, 2019.

40. Frysak Z, Schovanek J, Iacobone M and Karasek D: Insulin-like Growth Factors in a clinical setting: Review of IGF-I. Biomed Pap Med Fac Univ Palacky Olomouc Czech Repub 159: 347-351, 2015.
41. de la Monte SM, Tong M, Cohen AC, Sheedy D, Harper C and Wands JR: Insulin and insulin-like growth factor resistance in alcoholic neurodegeneration. Alcohol Clin Exp Res 32: $1630-1644,2008$

42. Madathil SK, Carlson SW, Brelsfoard JM, Ye P, D'Ercole AJ and Saatman KE: Astrocyte-specific overexpression of insulin-like growth factor-1 protects hippocampal neurons and reduces behavioral deficits following traumatic brain injury in mice. PLoS One 8: e67204, 2013.

43. Ferbert T, Child C, Graeser V, Swing T, Akbar M, Heller R, Biglari B and Moghaddam A: Tracking spinal cord injury: Differences in cytokine expression of IGF-1, TGF-B1, and sCD95I can be measured in blood samples and correspond to neurological remission in a 12 -week follow-up. J Neurotrauma 34: 607-614, 2017.

44. Muresanu DF, Sharma A, Lafuente JV, Patnaik R, Tian ZR, Nyberg F and Sharma HS: Nanowired delivery of growth hormone attenuates pathophysiology of spinal cord injury and enhances insulin-like growth factor-1 concentration in the plasma and the spinal cord. Mol Neurobiol 52: 837-845, 2015.

45. Galluzzi L, Morselli E, Vicencio JM, Kepp O, Joza N, Tajeddine N and Kroemer G: Life, death and burial: Multifaceted impact of autophagy. Biochem Soc Trans 36: 786-790, 2008.

46. Hayashi-Nishino M, Fujita N, Noda T, Yamaguchi A, Yoshimori T and Yamamoto A: A subdomain of the endoplasmic reticulum forms a cradle for autophagosome formation. Nat Cell Biol 11: $1433-1437,2009$

47. Kourtis $\mathrm{N}$ and Tavernarakis $\mathrm{N}$ : Autophagy and cell death in model organisms. Cell Death Differ 16: 21-30, 2009.

48. Kroemer G and Levine B: Autophagic cell death: The story of a misnomer. Nat Rev Mol Cell Biol 9: 1004-1010, 2008.

49. Levine B and Yuan J: Autophagy in cell death: An innocent convict? J Clin Invest 115: 2679-2688, 2005.

50. Wu YT, Tan HL, Huang Q, Ong CN and Shen HM: Activation of the PI3K-Akt-mTOR signaling pathway promotes necrotic cell death via suppression of autophagy. Autophagy 5: 824-834, 2009.

51. Klionsky DJ, Abdelmohsen K, Abe A, Abedin MJ, Abeliovich $\mathrm{H}$, Acevedo Arozena A, Adachi H, Adams CM, Adams PD, Adeli K, et al: Guidelines for the use and interpretation of assays for monitoring autophagy (3rd edition). Authophagy 12: 1-222, 2016.

52. Wang H, Wu Y, Han W, Li J, Xu K, Li Z, Wang Q, Xu K, Liu Y, Xie L, et al: Hydrogen Sulfide Ameliorates Blood-Spinal Cord Barrier Disruption and Improves Functional Recovery by Inhibiting Endoplasmic Reticulum Stress-Dependent Autophagy. Front Pharmacol 9: 858, 2018.

53. Wu J and Lipinski MM: Autophagy in neurotrauma: Good, bad, or dysregulated. Cells 8: 8, 2019.

54. Bai L, Mei X, Shen Z, Bi Y, Yuan Y, Guo Z, Wang H, Zhao H, Zhou Z, Wang C, et al: Netrin-1 improves functional recovery through autophagy regulation by activating the AMPK/mTOR signaling pathway in rats with spinal cord injury. Sci Rep 7: 42288, 2017.

55. Li J, Wang Q, Cai H, He Z, Wang H, Chen J, Zheng Z, Yin J, Liao Z, Xu H, et al: FGF1 improves functional recovery through inducing PRDX1 to regulate autophagy and anti-ROS after spinal cord injury. J Cell Mol Med 22: 2727-2738, 2018

56. Li Z, Liu F, Zhang L, Cao Y, Shao Y, Wang X, Jiang X and Chen Z: Neuroserpin restores autophagy and promotes functional recovery after acute spinal cord injury in rats. Mol Med Rep 17: 2957-2963, 2018.

57. Wang $\mathrm{P}$, Lin $\mathrm{C}$, Wu S, Huang $\mathrm{K}$, Wang $\mathrm{Y}$, Bao X, Zhang $\mathrm{F}$, Huang $\mathrm{Z}$ and Teng $\mathrm{H}$ : Inhibition of autophagy is involved in the protective effects of ginsenoside Rb1 on spinal cord injury. Cell Mol Neurobiol 38: 679-690, 2018.

58. Bianchi VE, Locatelli V and Rizzi L: Neurotrophic and neuroregenerative effects of GH/IGF1. Int J Mol Sci 18: 18, 2017.

59. Marín-Aguilar F, Castejón-Vega B, Alcocer-Gómez E, Lendines-Cordero D, Cooper MA, de la Cruz P, Andújar-Pulido E, Pérez-Alegre M, Muntané J, Pérez-Pulido AJ, et al: NLRP3 Inflammasome Inhibition by MCC950 in Aged Mice Improves Health via Enhanced Autophagy and PPAR $\alpha$ Activity. J Gerontol A Biol Sci Med Sci 75: 1457-1464, 2020.

60. Marín-Aguilar F, Lechuga-Vieco AV, Alcocer-Gómez E, Castejón-Vega B, Lucas J, Garrido C, Peralta-Garcia A, Pérez-Pulido AJ, Varela-López A, Quiles JL, et al: NLRP3 inflammasome suppression improves longevity and prevents cardiac aging in male mice. Aging Cell 19: e13050, 2020. 
61. Zhang HY, Wang ZG, Wu FZ, Kong XX, Yang J, Lin BB, Zhu SP, Lin L, Gan CS, Fu XB, et al: Regulation of autophagy and ubiquitinated protein accumulation by bFGF promotes functional recovery and neural protection in a rat model of spinal cord injury. Mol Neurobiol 48: 452-464, 2013.

62. Renna M, Bento CF, Fleming A, Menzies FM, Siddiqi FH, Ravikumar B, Puri C, Garcia-Arencibia M, Sadiq O, Corrochano $\mathrm{S}$, et al: IGF-1 receptor antagonism inhibits autophagy. Hum Mol Genet 22: 4528-4544, 2013.

63. Jean S and Kiger AA: Classes of phosphoinositide 3-kinases at a glance. J Cell Sci 127: 923-928, 2014

64. Gulluni F, De Santis MC, Margaria JP, Martini M and Hirsch E: Class II PI3K functions in cell biology and disease. Trends Cell Biol 29: 339-359, 2019.

65. Alliouachene S, Bilanges B, Chicanne G, Anderson KE, Pearce W, Ali K, Valet C, Posor Y, Low PC, Chaussade C, et al Inactivation of the class II PI3K-C2 $\beta$ potentiates insulin signaling and sensitivity. Cell Rep 13: 1881-1894, 2015.

66. Valet C, Chicanne G, Severac C, Chaussade C, Whitehead MA, Cabou C, Gratacap MP, Gaits-Iacovoni F, Vanhaesebroeck B, Payrastre B, et al: Essential role of class II PI3K-C2 $\alpha$ in platelet membrane morphology. Blood 126: 1128-1137, 2015.

67. Yu X, Long YC and Shen HM: Differential regulatory functions of three classes of phosphatidylinositol and phosphoinositide 3-kinases in autophagy. Autophagy 11: 1711-1728, 2015.

68. Vanhaesebroeck B, Guillermet-Guibert J, Graupera M and Bilanges B: The emerging mechanisms of isoform-specific PI3K signalling. Nat Rev Mol Cell Biol 11: 329-341, 2010.

69. Okada S, Hara M, Kobayakawa K, Matsumoto Y and Nakashima Y: Astrocyte reactivity and astrogliosis after spinal cord injury. Neurosci Res 126: 39-43, 2018.

70. Chen CH, Sung CS, Huang SY, Feng CW, Hung HC, Yang SN, Chen NF, Tai MH, Wen ZH and Chen WF: The role of the $\mathrm{PI} 3 \mathrm{~K} / \mathrm{Akt} / \mathrm{mTOR}$ pathway in glial scar formation following spinal cord injury. Exp Neurol 278: 27-41, 2016.

71. Hou H, Zhang L, Zhang L and Tang P: Acute spinal cord injury in rats should target activated autophagy. J Neurosurg Spine 20: $568-577,2014$
72. Goldshmit Y, Kanner S, Zacs M, Frisca F, Pinto AR, Currie PD and Pinkas-Kramarski R: Rapamycin increases neuronal survival, reduces inflammation and astrocyte proliferation after spinal cord injury. Mol Cell Neurosci 68: 82-91, 2015.

73. Latacz A, RussellJA,OcłonE,Zubel-łojekJ andPierzchała-KoziecK: mTOR pathway - novel modulator of astrocyte activity. Folia Biol (Krakow) 63: 95-105, 2015.

74. Muñoz-Galdeano T, Reigada D, Del Águila Á, Velez I, Caballero-López MJ, Maza RM and Nieto-Díaz M: Cell specific changes of autophagy in a mouse model of contusive spinal cord injury. Front Cell Neurosci 12: 164, 2018.

75. Sarkar C, Zhao Z, Aungst S, Sabirzhanov B, Faden AI and Lipinski MM: Impaired autophagy flux is associated with neuronal cell death after traumatic brain injury. Autophagy 10: 2208-2222, 2014.

76. Fang B, Li XQ, Bao NR, Tan WF, Chen FS, Pi XL, Zhang Y and Ma $\mathrm{H}$ : Role of autophagy in the bimodal stage after spinal cord ischemia reperfusion injury in rats. Neuroscience 328: 107-116, 2016.

77. Woelfle J, Chia DJ, Massart-Schlesinger MB, Moyano P and Rotwein P: Molecular physiology, pathology, and regulation of the growth hormone/insulin-like growth factor-I system. Pediatr Nephrol 20: 295-302, 2005.

78. Ranke MB, Wölfle J, Schnabel D and Bettendorf M: Treatment of dwarfism with recombinant human insulin-like growth factor-1. Dtsch Arztebl Int 106: 703-709, 2009.

79. Mukhamedshina YO, Gilazieva ZE, Arkhipova SS, Galieva LR, Garanina EE, Shulman AA, Yafarova GG, Chelyshev YA, Shamsutdinova NV and Rizvanov AA: Electrophysiological, Morphological, and Ultrastructural Features of the Injured Spinal Cord Tissue after Transplantation of Human Umbilical Cord Blood Mononuclear Cells Genetically Modified with the VEGF and GDNF Genes. Neural Plasticity 2017: 9857918, 2017.

This work is licensed under a Creative Commons Attribution-NonCommercial-NoDerivatives 4.0 International (CC BY-NC-ND 4.0) License. 